IZA DP No. 1132

\title{
Non-Linearities in the Expansion of Capital Stock
}

Sher Verick

Wilko Letterie

Gerard Pfann

May 2004 


\title{
Non-Linearities in the Expansion of Capital Stock
}

\author{
Sher Verick \\ University of Bonn and IZA Bonn \\ Wilko Letterie \\ Maastricht University \\ Gerard Pfann \\ Maastricht University, \\ CEPR and IZA Bonn
}
Discussion Paper No. 1132
May 2004

IZA

P.O. Box 7240

53072 Bonn

Germany

Phone: +49-228-3894-0

Fax: +49-228-3894-180

Email: iza@iza.org

Any opinions expressed here are those of the author(s) and not those of the institute. Research disseminated by IZA may include views on policy, but the institute itself takes no institutional policy positions.

The Institute for the Study of Labor (IZA) in Bonn is a local and virtual international research center and a place of communication between science, politics and business. IZA is an independent nonprofit company supported by Deutsche Post World Net. The center is associated with the University of Bonn and offers a stimulating research environment through its research networks, research support, and visitors and doctoral programs. IZA engages in (i) original and internationally competitive research in all fields of labor economics, (ii) development of policy concepts, and (iii) dissemination of research results and concepts to the interested public.

IZA Discussion Papers often represent preliminary work and are circulated to encourage discussion. Citation of such a paper should account for its provisional character. A revised version may be available on the IZA website (www.iza.org) or directly from the author. 
IZA Discussion Paper No. 1132

May 2004

\section{ABSTRACT}

\section{Non-Linearities in the Expansion of Capital Stock}

The empirical identification of non-linearities in investment relies on how investment is assumed to be separated into various regimes. Using German establishment-level panel data, we estimate a two-regime model of replacement and expansion investment which allows us to observe regime separation, an aspect of the data that is typically absent from previous empirical studies. Our results indicate that firms tend to spread the expansion of capital stock over a period of years rather than concentrating investment in a single year. Moreover, there is evidence that investment is more sensitive to fundamentals in the high regime, where establishments both replace and expand capital stock, than in the low regime, where they only invest in replacement. Finally, correcting for endogenous sample selection indicates that this source of bias does not affect the coefficient estimates significantly.

JEL Classification: E22, C23, C24

Keywords: investment, non-convex adjustment costs, sample selection bias, panel data

Corresponding author:

Sher Verick

IZA Bonn

P.O. Box 7240

53072 Bonn

Germany

Email: verick@iza.org

\footnotetext{
${ }^{*}$ Financial support for Verick from IZA and the Deutsche Forschungsgemeinschaft (DFG) is gratefully acknowledged. We thank seminar participants at IZA, and the Labour Econometrics Workshop, Melbourne. The data used in this paper is maintained by the Institut für Arbeitsmarkt- und Berufsforschung (IAB), Bundesagentur für Arbeit, Nürnberg, Germany, and we thank Holger Alda for his help and cooperation. The usual disclaimer applies.
} 


\section{Introduction}

Though non-convex adjustment costs were considered earlier in the investment literature by Rothschild (1971) and Nickell (1978), Abel and Eberly (1994) were the first to specify a model with an augmented adjustment cost function consisting of both fixed and kinked-linear costs in a Q model of investment. More recently a number of empirical papers have estimated models with non-convex adjustment costs using firm-level panel data. These studies have primarily investigated whether the response of firm investment to "fundamentals" is non-linear, which can be argued to result from the presence of non-convexities in adjustment costs. ${ }^{1}$ However, in this literature, the evidence for non-convex adjustment costs relies on the identification of different investment regimes. As discussed in this paper, this approach is unlikely to be an accurate reflection of the true investment behaviour of firms.

We add further detail to these types of investment models by assuming that a firm faces two decisions: investment in replacement; and investment in the expansion of capital stock. ${ }^{2}$ Previous studies such as Barnett and Sakellaris (1998), Nilsen and Schiantarelli (2003), and Letterie and Pfann (2003) estimate models where the regime chosen by a firm is determined endogenously by the estimation procedure. To estimate our model we exploit the IAB Establishment Panel, which is a dataset maintained by the Institut für Arbeitsmarkt und Berufsforschung (IAB) in Nürnberg, Germany. The main advantage of this panel dataset is that it distinguishes between expansion and replacement investment. As a consequence, our

\footnotetext{
${ }^{1}$ See for example Caballero, Engel, and Haltiwanger (1995), Barnett and Sakellaris (1998), Doms and Dunne (1998), Hu and Schiantarelli (1998), Cooper, Haltiwanger, and Power (1999), Abel and Eberly (2001), Nilsen and Schiantarelli (2003), and Letterie and Pfann (2003).

${ }^{2}$ In this paper the term firm equates to the establishment since the data used for the analysis is collected at this level. The capital stock variable can be considered to be an aggregate measure of different types of capital.
} 
data allows us to determine the regime chosen by a firm directly, without using estimation procedures like the studies mentioned above. Furthermore, these two types of investment are likely to involve different adjustments costs. In this respect, it is plausible that replacement of capital stock, which is required due to capital depreciation, incurs only convex adjustment costs and hence firms find it optimal to invest continuously to spread costs over time, albeit at a lower rate than in the absence of adjustment costs. On the other hand, investment in the expansion of the capital stock, which is required if firms wish to increase output, could be assumed here to incur both convex and fixed adjustment costs. By introducing non-convexities into a model, expansion of the capital stock will be characterised by periods of inaction where firms do not invest. As seen in the data, total investment is zero in only $6.8 \%$ of observations while firms do not expand capital stock in around $30 \%$ of observations. This indicates that though non-convex adjustment costs are likely to be present for replacement investment, they are far more substantial in the case of expansion investment.

Given this setting, the focus of this paper is how establishments expand capital stock in a dynamic setting and whether investment responds differently to fundamentals in the two investment regimes: the low regime where firms are only replacing capital stock; and a high regime where firms are investing in both expansion and replacement. If the adjustment costs incurred in the two regimes differ due to higher non-convex costs, then we would expect to see a non-linearity in the investment profile. To identify this we estimate a model for total investment separately for the high and low regimes. Furthermore, in the presence of non-convex adjustment costs, firms are not expanding the capital stock continuously resulting in zero expansion investment during such periods. This is an example of a corner solution and since 
the decision to expand capital stock is endogenous, failure to control for selection is likely to result in biased estimates. To correct estimates for endogenous sample selection bias we employ a two-step random-effects parametric methodology for panel data as developed by Vella and Verbeek (1999), which is an extension to Heckman's two-step procedure by allowing for correlation between both the time-invariant error terms and the time-variant idiosyncratic error terms.

The paper is organised as follows. In Section 2, we specify the econometric model and outline the derivation of the bias correction terms. The model is then estimated using the IAB Establishment panel which is discussed in Section 3 with the results presented in Section 4. Finally, in Section 5 we conclude.

\section{Econometric model and estimation}

Following the approach of Abel and Eberly (1994) and given the conditions of Hayashi (1982), it is straightforward to derive a Q model of investment where the investment rate is determined by fundamentals represented by average $q .{ }^{3}$ As a structural model, it is possible to recover estimates of the underlying structural adjustment cost parameters. However, the focus here is to investigate how investment responds to fundamentals, and whether estimates are biased by endogenous sample selection, rather than to derive estimates of adjustment costs which are only used to motivate the estimation strategy. Given that firms do not invest at all in certain periods, we need to assume that replacement investment incurs both convex and non-convex adjustment costs. However, since the rate of censoring for expansion investment is much higher, there is in addition to these costs an extra fixed cost

\footnotetext{
${ }^{3}$ For details on average $q$ see Appendix B.
} 
when expanding the capital stock. These assumptions yield a three regime switching model: a zero investment regime; a low regime where firms only invest in the replacement of capital stock; and a high regime where firms invest in both replacement and expansion of capital. For the purposes of identifying the responsiveness of investment, we focus only on the regimes where total investment is non-zero. Clearly, in the regime where no investment is undertaken, the responsiveness to fundamentals is zero. Thus, conditional on firms having already decided to invest, we can derive the following specification for investment over the high and low regimes

$$
\left(\frac{I}{K}\right)_{i t}= \begin{cases}\left(\frac{I^{r}}{K}\right)_{i t}+\left(\frac{I^{e}}{K}\right)_{i t} & \text { iff } \pi_{i t}=1 \\ \left(\frac{I^{r}}{K}\right)_{i t} & \text { iff } \pi_{i t}=0\end{cases}
$$

where $I_{i t}$ is total investment by firm $i, i=(1, \ldots, N)$, in period $t, t=(0, \ldots, T), I_{i t}^{r}$ is investment in the replacement of capital stock, $K_{i t}$, and $I_{i t}^{e}$ is investment in the expansion of capital. ${ }^{4}$ The binary variable $\pi_{i t}$ in (1) represents the selection rule; when $\pi_{i t}=1$, firm $i$ invests in both replacement and expansion of capital stock in period $t$, and similarly when $\pi_{i t}=0$, the firm only replaces capital stock in that period. In most datasets this type of sample separation is unobservable but here we are able to observe firm investment in both the high and low regimes. To estimate model (1), we use the following econometric specification

$$
\left(\frac{I}{K}\right)_{i t}=\left\{\begin{array}{cc}
\alpha_{e}\left(\frac{Y}{K}\right)_{i, t-1}+\gamma_{e}\left(\frac{Y}{K}\right)_{i, t-1}^{2}+\beta_{e}^{\prime} X_{i t}+\mu_{i}^{e}+\epsilon_{i t}^{e} \quad \text { iff } \pi_{i t}=1 \\
\alpha_{r}\left(\frac{Y}{K}\right)_{i, t-1}+\gamma_{r}\left(\frac{Y}{K}\right)_{i, t-1}^{2}+\beta_{r}^{\prime} X_{i t}+\mu_{i}^{r}+\epsilon_{i t}^{r} \quad \text { iff } \pi_{i t}=0
\end{array}\right.
$$

\footnotetext{
${ }^{4} K_{i t}$ is the level of the capital stock at the beginning of period $t$.
} 
where the lagged sales-capital ratio $Y / K_{i, t-1}$ and its quadratic proxy for investment fundamentals. $X_{i t}$ is a vector of sector and year dummies. We include sector dummies to capture unobserved sectoral differences and year dummies to approximate any macroeconomic trends. Finally, we have assumed in the specification above that the error terms are not restricted to being equal in both regimes. In particular, $\mu_{i}^{n}$ is the unobserved firm-specific time-invariant effect, and $\epsilon_{i t}^{n}$ is the idiosyncratic time-variant error term, where $n \in\{r, e\}$. Distributional assumptions are stated below.

To be more precise about the selection rule, we specify it as the following latent variable model

$$
\pi_{i t}=\left\{\begin{array}{c}
1 \quad \text { iff } \pi_{i t}^{*}>0 \\
0 \quad \text { iff } \pi_{i t}^{*} \leq 0
\end{array}\right.
$$

where the latent variable equation $\pi_{i t}^{*}$ is specified as

$$
\pi_{i t}^{*}=\eta \pi_{i, t-1}+\gamma^{\prime} z_{i t}+\tau_{i}+\theta_{i t}
$$

where $z_{i t}$ is a vector of sector and year dummies in addition to the lagged salescapital ratio $Y / K_{i, t-1}$ and its quadratic. Of particular interest is the analysis of state dependence in the selection rule by including the dummy for expansion investment in the previous period $\pi_{i, t-1}$ in the specification. This enables us to identify whether there is true state dependence as opposed to unobserved heterogeneity. In our setting, it is possible that firms continue to expand due to unobserved factors which are time-invariant such as firm and management efficiency. However, we wish to identify the impact of expanding in the previous period on the current decision 
independent of such factors, which would not be possible with a static model. Since we have assumed that expansion in capital stock involves fixed costs of adjustment, $\eta$ should be negative to reflect that firms find it optimal to make lumpy investments in expansion followed by periods where they do not expand capital stock. If $\eta$ turns out to be positive, this could indicate that convex adjustment costs dominate. The selection rule represented by equations (3) and (4), is a reduced-form specification. However, in our setting, the selection rule has a structural-type interpretation since it is based on the condition required for firms to find it optimal to invest in expansion of capital stock, which is a function of fixed costs amongst other parameters. The fixed cost parameter is not directly estimated and in order to identify such a parameter, estimation of a structural discrete decision model would be required.

The vector of control variables $z_{i t}$ in the selection model (4) should include some exclusion restrictions that would improve identification of the parameters and additionally are of economic interest, though, identification in the absence of exclusion restrictions should be less of a problem with the methodology employed. In this respect, we restrict the lagged dummy for expansion to the selection equation only. This variable is a valid exclusion restriction if it is only correlated with the decision to expand in the current period but given that the firm has decided to expand, it is not correlated with the total investment rate.

\section{Controlling for endogenous sample selection in a panel data model}

We implement the two-step estimator of Vella and Verbeek (1999) which is used to construct bias correction terms to control for endogenous sample selection. This bias occurs since the selection into the two investment regimes is endogenous. Here 
we are ignoring the potential selection bias resulting from the initial decision to invest or not. However, given that the rate of censoring is much higher for expansion than total investment, we expect that if such a bias is present, then it should be identified for the selection between the replacement and expansion regimes. If there is no evidence of this bias, then it is unlikely to be identified for the initial selection. The extension of the methodology employed here over other techniques used is that it distinguishes whether the bias is operating through the correlation between the time-invariant and/or time-variant error terms. This is preferable to assuming that the only source of bias operates through the time-invariant term and estimating the model as a first-differences or fixed-effect specification, since such transformations can potentially increase the bias due to measurement error as discussed in Griliches and Hausman (1986). ${ }^{5}$ Alternatively, estimating the model using Heckman's twostep approach assumes that the selection is only occurring through the time-variant error term, which should be tested rather than assumed. Thus, these empirical methods are not necessarily the simple solution and the approach taken here allows one to investigate the role of endogenous sample selection bias in a more general setting.

We start by assuming that the error terms in both the primary equation (2) and the selection equation (4) are jointly normally distributed

\footnotetext{
${ }^{5}$ Given the use of a proxy for average $q$ and capital stock in this model, measurement error is likely to be present.
} 


\section{Assumption 1 (Distribution of error terms)}

$$
\left(\begin{array}{c}
\bar{\epsilon}_{i}^{r} \\
\bar{\epsilon}_{i}^{e} \\
\bar{\theta}_{i} \\
\mu_{i}^{r} \\
\mu_{i}^{e} \\
\tau_{i}
\end{array}\right) \sim N\left(0,\left(\begin{array}{cccccc}
\sigma_{\epsilon^{r}}^{2} I_{T} & & & & & \\
\sigma_{\epsilon^{r} \epsilon^{e}} I_{T} & \sigma_{\epsilon^{e}}^{2} I_{T} & & & & \\
\sigma_{\epsilon^{r} \theta} I_{T} & \sigma_{\epsilon^{e} \theta} I_{T} & \sigma_{\theta}^{2} I_{T} & & & \\
0 & 0 & 0 & \sigma_{\mu^{r}}^{2} & & \\
0 & 0 & 0 & \sigma_{\mu^{r} \mu^{e}} & \sigma_{\mu^{e}}^{2} & \\
0 & 0 & 0 & \sigma_{\mu^{r} \tau} & \sigma_{\mu^{e} \tau} & \sigma_{\tau}^{2}
\end{array}\right)\right),
$$

where $\bar{\epsilon}_{i}^{n}=\left\{\epsilon_{i 1}^{n} \ldots \epsilon_{i T}^{n}\right\}$ for $n=\{r, e\}, \bar{\theta}_{i}=\left\{\theta_{i 1} \ldots \theta_{i T}\right\}$, and $I_{T}$ is a $T \times T$ identity matrix. Thus the firm-specific effects, $\mu$ and $\tau$, in the primary equation (2) and the selection equation (4) are allowed to be correlated and similarly with the covariance between the idiosyncratic error terms, $\epsilon$ and $\theta$. The covariance between the $\mu^{r}$ and $\mu^{e}$, and likewise, between $\epsilon^{r}$ and $\epsilon^{e}$ are allowed to be non-zero. Other covariances are assumed to be zero. This correlation structure defines how the bias enters estimation of the primary equation. Furthermore, we assume that the vector of control variables in the primary equation, $x_{i t}$ is strictly exogenous. Heteroskedasticity and autocorrelation is allowed for in $\epsilon_{i t}$ in the primary equation. Moreover, we need to assume

Assumption 2 Conditional on $\tau_{i}, \theta_{i t}$ is independent over time and firms.

As in Heckman's two-step approach, to derive the two bias correction terms, we write equation (2) conditional on the vector of selection into expansion investment for periods $t=(1, \ldots, T), \pi_{i}=\left(\pi_{i 1}, \pi_{i 2}, \ldots, \pi_{i T}\right)^{\prime}$, selection in the initial period $\pi_{i 0}$, and the vectors of control variables $z_{i}=\left(z_{i 1}, \ldots, z_{i T}\right)^{\prime}$ resulting in 


$$
E\left[\left(\frac{I}{K}\right)_{i t} \mid \pi_{i}, \pi_{i 0}, z_{i}\right]=\alpha_{n}\left(\frac{Y}{K}\right)_{i, t-1}+\gamma_{n}\left(\frac{Y}{K}\right)_{i, t-1}^{2}+\beta_{n}^{\prime} X_{i t}+E\left[v_{i t}^{n} \mid \pi_{i}, \pi_{i 0}, z_{i}\right]
$$

where $n=\{r, e\}$. Estimates of $\hat{\alpha}_{n}, \hat{\gamma}_{n}$, and $\hat{\beta}_{n}$ are inconsistent and biased if the conditional expectation of the error term is not zero, that is, $E\left[v_{i t}^{n} \mid \pi_{i}, \pi_{i 0}, z_{i}\right] \neq 0$. Following Vella and Verbeek (1999), the conditional expectation of the error term in equation (5) can be shown to equal

$$
E\left[v_{i t}^{n} \mid \pi_{i}, \pi_{i 0}, z_{i}\right] \equiv \lambda_{1 n} B 1_{i}+\lambda_{2 n} B 2_{i t}
$$

where $n=\{r, e\}$. The two correction terms $B 1_{i}$ and $B 2_{i t}$ are functions of the parameters used in the first-stage, the estimation of the selection rule equation (3), and are derived using the likelihood contribution for the individual firm $i$ in the randomeffects probit model setting, and the generalised residual from the cross-sectional probit model, which involves the numerical evaluation of two one-dimensional integrals. The procedure to calculate the terms in (6) is fully explained in Appendix A. The derived bias correction terms, $B 1_{i}$ and $B 2_{i t}$, are then used as additional regressors in the estimation of the primary equation, which is analogous to the use of the inverse Mills' ratio as an additional regressor in Heckman's sample selection model. The parameter estimates for these correction terms are $\hat{\lambda_{1}}$ and $\hat{\lambda_{2}}$, and indicate whether the endogenous sample selection is due to time-invariant or time-variant factors. Under the assumption of joint normality, these coefficients are estimates of the covariances of the error terms such that $\hat{\lambda}_{1} \equiv \hat{\sigma}_{n, \mu \tau}$ and $\hat{\lambda}_{2} \equiv \hat{\sigma}_{n, \epsilon \theta}$, $n=\{r, e\}$. Identification requires that there is a non-linear mapping from the variables in the selection equation (4) to these bias correction terms $B 1_{i}$ and $B 2_{i t}$ (Vella 
and Verbeek 1999). Furthermore, the lagged dummy for expansion is excluded from the investment equation and thus will serve as an exclusion restriction, which should improve identification of the bias correction terms.

Another issue that has to be addressed in our model is the initial conditions problem since our latent equation (4) includes a dummy for expansion in the previous period. Due to the nature of the firm-level panel data, it is not possible to argue that expansion in the initial period $\pi_{i 0}$ is exogenous and does not depend on the unobserved firm-effect $\tau_{i}$ in equation (4). Typically what is done is to follow the approach of Heckman (1981) to derive an expression for the marginal distribution of selection in the initial period given $z_{i}$ and $\tau_{i}, f\left(\pi_{i 0} \mid z_{i}, \tau_{i}\right)$. An alternative is to use an approach suggested by Wooldridge (2002). ${ }^{6}$ We use the approach of Heckman (1981), which is discussed further in Appendix A. Finally, we make the following normalisation: $\sigma_{\theta}^{2}=1$.

Using German establishment panel data, we estimate the multiple regime model for total investment, equation (2), separately for the high and low regimes. This way we can identify whether the coefficients, $\alpha$ and $\gamma$, vary across these two regimes, which would imply that the response of total investment to fundamentals is nonlinear.

\footnotetext{
${ }^{6}$ This methodology is similar to that of Chamberlain (1980), and requires deriving a density for $\tau_{i}$ given selection in the initial period $\pi_{i 0}$ and the exogenous variables $z_{i}, f\left(\tau_{i} \mid \pi_{i 0}, z_{i}\right)$. Rather than finding the joint distribution of selection $f\left(\pi_{i}, \pi_{i 0} \mid z_{i}\right)$ as in Heckman's approach, this method obtains the joint distribution of selection in period $1, \ldots, T$ given $\pi_{i 0}$ and $z_{i}, f\left(\pi_{i} \mid \pi_{i 0}, z_{i}\right)$.
} 


\section{Data and summary statistics}

For estimation we use the IAB Establishment Panel, a dataset administered by Institut für Arbeitsmarkt- und Berufsforschung (IAB) in Nürnberg, Germany. ${ }^{7}$ The panel started in 1993 with around 4000 establishments, with almost 14,000 participating in 2000. The sample for the dataset is drawn from the employment statistics register of the Federal Employment Services (Bundesagentur für Arbeit) which covers all establishments with at least one employee (or trainee) that is subject to social security provisions. The dataset contains information on employment, investment (replacement and expansion) and firm sales. However, there is no measure for the capital stock and thus a proxy variable is required. Following Letterie and Pfann (2003), observations from the period 1992-1995 for investment and sales are used to construct a capital stock measure. Since data for expansion investment only begins in 1996, this use of the data does not reduce the potential length of the panel. However, since many firms do not provide details for investment and turnover in every year, the need to construct the proxy reduces the sample size considerably. The (unbalanced) panel used for estimation consists of large West German manufacturing firms. Since we have specified a lagged dependent variable in the selection equation, our final panel of firms covers only 5 years, 1997-2001. The variables used for estimation and the construction of the capital stock proxy are further described in Appendix B.

In Table 1, the summary statistics of the main variables of interest are listed. Total investment is on average DM 17.3 million and is censored at zero in $6.8 \%$ of observations. The median investment is DM 4.5 million which reflects the presence of

\footnotetext{
${ }^{7}$ See betriebspanel.iab.de for further details.
} 
some large observations which skew the distribution. On the other hand, expansion investment, which is a component of total investment, is on average DM 5.8 million with around $30 \%$ of observations censored at zero. The rate of zero expansion investment also varies over time. In 1997 and 1998, around 28\% of firms did not expand, which then increased to $32 \%$ in 1999, before dropping again to $30 \%$ in 2000. In 2001 , the rate was at around $33 \%$. The average total investment rate $I / K$ is $8.2 \%$; $8.8 \%$ for firms in the high regime (replacement and expansion) and $6.7 \%$ for firms in the low regime (replacement only). Firms in the sample are on average very large with almost 1120 employees and annual sales of DM 444 million. As seen in Table 1, the firms in the high regime are on average larger in terms of investment (DM 20.4 million cf. DM 9.7 million), sales (DM 491 million cf. DM 331 million) and employment (1303 cf. 670) than those in the low regime. Interestingly, the lagged sales-capital ratio is on average larger in the low regime than in the high one. This result contradicts the identification of investment sensitivity in previous papers which endogenously determined separation of regimes based on a measure of investment fundamentals such as the sales-capital ratio. If this measure was to be used to determine the different investment regimes, then what we call the low regime would be identified as a "high" one and vice-versa for the high regime. This illustrates the fundamental identification problem when the separation of the regimes is not observed.

In the subsample of firms which are in the panel for all 5 years, $41 \%$ expand in every year, $26 \%$ in 4 out of the 5 years and $13 \%$ in 3 out of 5 years, while $6 \%$ expand twice and once during this 1997-2001. Furthermore, only $7 \%$ of these firms did not expand capital stock at all over this period. Moreover, in around $2 \%$ of observations replacement investment was zero, that is, total investment was only for expansion 
Figure 1: Distribution of Investment Rate (I/K)

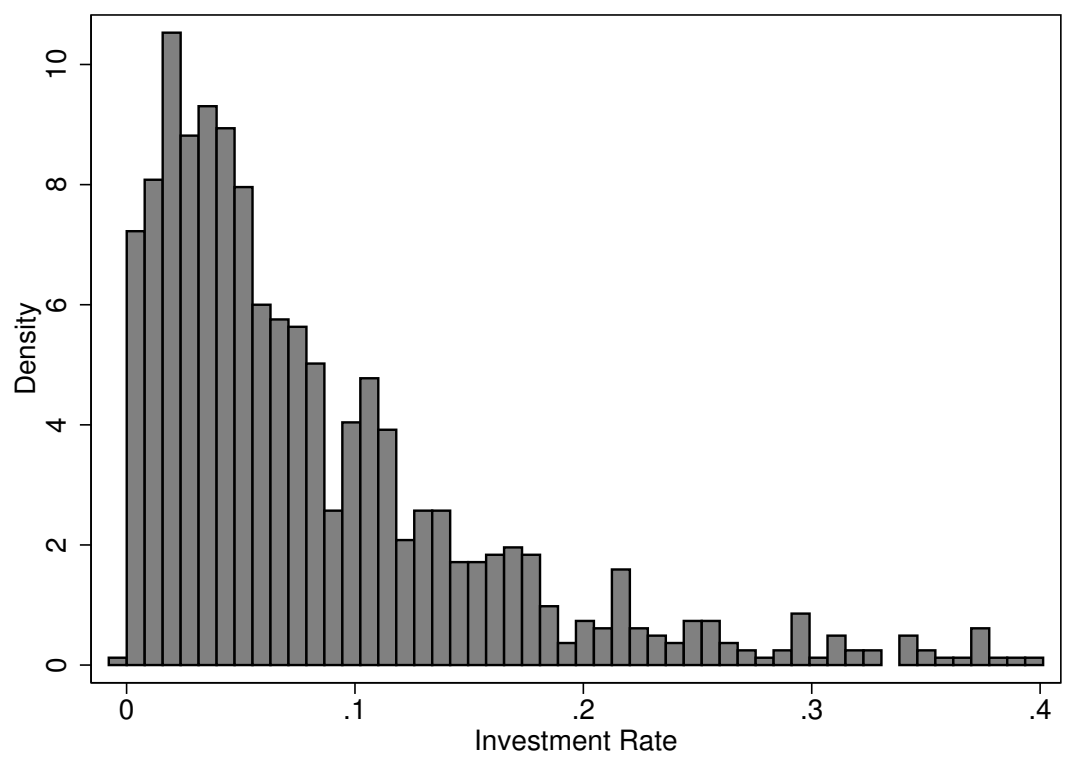

Source: IAB Establishment Panel 1996-2001. Graphed using Stata 8.0.

of the capital stock. These firms are smaller on average and thus may include startups which were experiencing rapid growth. Given this preliminary evidence, it is likely that 5 years is a rather short time-frame to capture the effect of non-convex adjustment costs on firm behaviour and that the firms tend to expand capital stock over a number of years.

The distribution of the total investment rate is displayed in Figure 1, which indicates that there is a clustering of investment rates around the lower end of the distribution, and moreover, there are not many observations at the right-tail of the distribution. In Figure 2 the distribution of the total investment rate is graphed separately for the two regimes; the left graph is for the low regime where establishments are only replacing capital stock, and the right graph is for the high regime where they invest in both replacement and expansion of capital. These graphs indicate that there are more observations at the lower end of the distribution 


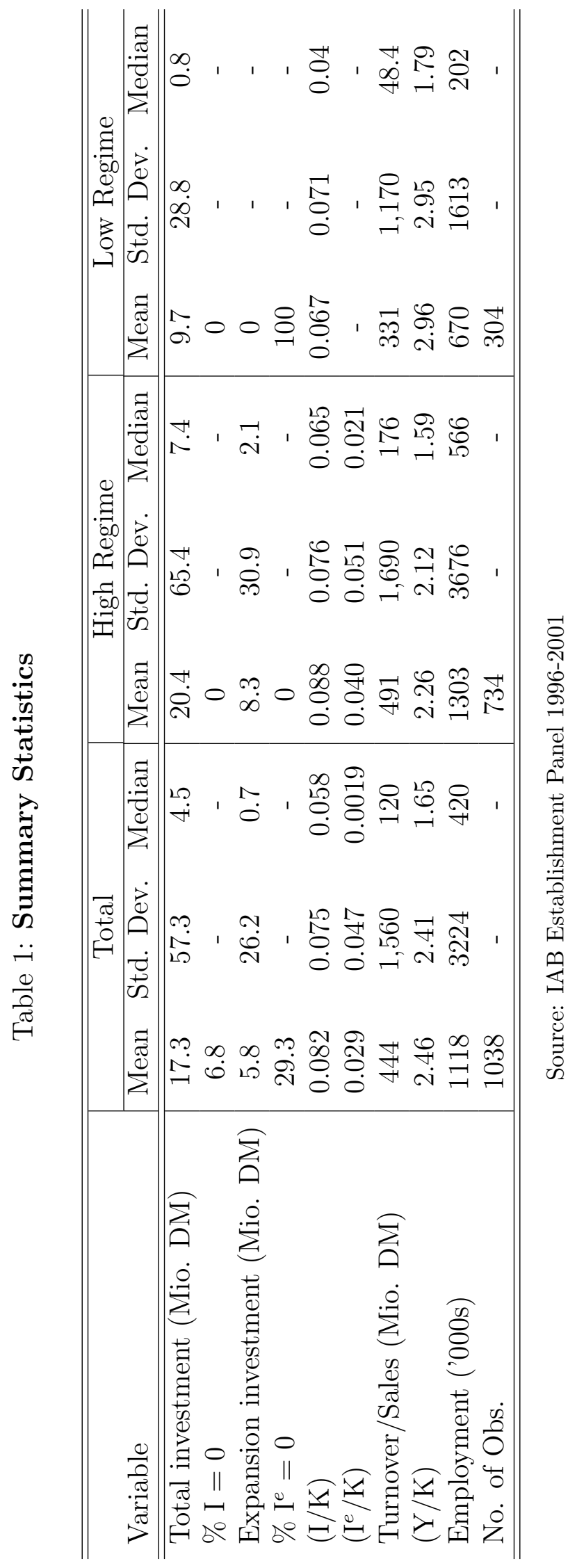


Figure 2: Distribution of Investment Rate (I/K) by Regime

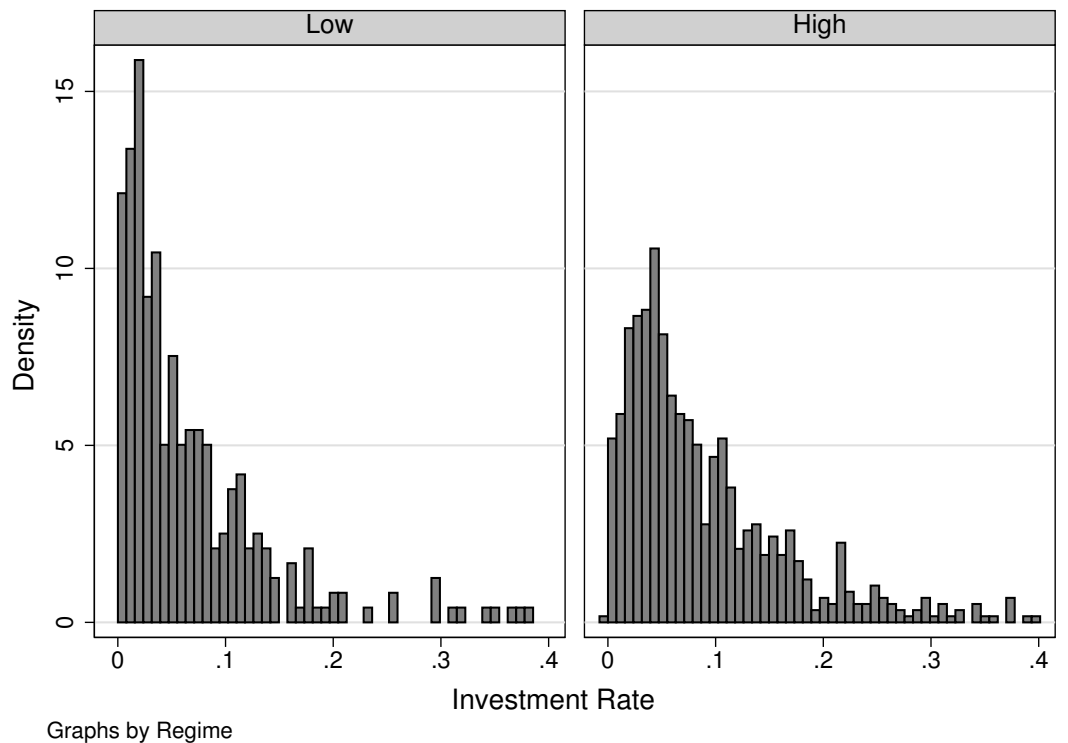

Source: IAB Establishment Panel 1996-2001. Graphed using Stata 8.0.

for the low regime and there are more cases at higher levels of investment rate for the high regime. As the separation of investment into different regimes has typically been unobserved in the previous literature, an ad-hoc definition of a "spike" in investment has been discussed, which was defined as occurring when the investment rate is above 0.2 or $20 \%$. Using this definition, around $8 \%$ of observations in our sample could be classified as a spike. However, of these cases, $19 \%$ are in the low regime where firms do not expand capital stock. Furthermore, where investment is not a spike, expansion occurs in $70 \%$ of these observations. Thus, there are many cases of investment where firms expand but are not a spike according to previous definitions and vice-versa. Therefore, such ad-hoc thresholds are unlikely to be an accurate reflection of firms' investment behaviour. 


\section{Results}

\section{Random-effects probit model}

As discussed in Section 2, firms face two decisions: the decision to invest; and conditional on investing, the decision whether or not to expand capital stock. We focus on the second decision and use the subsample where total investment is positive for estimation of the selection and multiple-regime models. To investigate the dynamics of capital expansion, equation (4) is estimated as a random-effects probit model jointly with the probit for expansion in the initial period as per the methodology of Heckman (1981). The results of the random-effects probit model are displayed in Table 2, and indicate that the coefficient for the lagged dummy for expansion is positive and significant at the $1 \%$ level, which implies that firms which expand in the previous period are more likely to expand in the current period. This result indicates that firms tend to spread investment in the expansion of the capital stock over at least two periods, which is consistent with the summary statistics. Since we have controlled for unobserved time-invariant heterogeneity by integrating $\tau_{i}$ out of equation (4), this is evidence of true state dependence. Surprisingly, the coefficient for the sales-capital ratio is negative but it is not statistically significant. This could result from the inclusion of the lagged dependent variable, which captures all the effects of economic conditions in the previous period. However, the coefficient remains negative and insignificant when estimating equation (4) without the lagged dependent variable. As shown in Table 2, $\rho$ is equal to 0.331, which implies that around $33 \%$ of the total variation of the unobservable error is due to the time-invariant term. This indicates that the random-effects probit estimator is significantly different from the standard probit estimator which does not exploit the panel-dimension of the data and is inconsistent in the presence of correlated errors. The estimates for the sector dummies indicate that the consumer good (textiles, food, tobacco, clothing and leather), the paper and printing, the plastic and rubber goods, the glass, ceramic, processed stone and earth, and the metal industries are less likely to expand capital stock in comparison to the machinery industry. Surprisingly, there is no evidence of macroeconomic trend effects as captured by year 
Table 2: Selection Equation - Expansion Investment

\begin{tabular}{lc}
\hline \hline Dependent variable: $\mathcal{I}\left(I_{t}^{e} \neq 0\right)$ & \\
\hline Variable & Coefficient \\
\hline \hline $\mathcal{I}\left(I_{t-1}^{e} \neq 0\right)$ & $0.511^{* * *}$ \\
& $(0.157)$ \\
$(Y / K)_{t-1}$ & -0.049 \\
& $(0.065)$ \\
$(Y / K)_{t-1}^{2}$ & -0.002 \\
& $(0.005)$ \\
$\rho$ & $0.331^{* * *}$ \\
No. Obs. & $(0.095)$ \\
Log likelihood & 1038 \\
\hline \hline
\end{tabular}

Source: IAB Establishment Panel 1996-2001. *** - 1\% significance level, ${ }^{* *}-5 \%$ significance level, ${ }^{*}-10 \%$ significance level. $\mathcal{I}$ is an indicator variable and equals 1 if the condition inside the parentheses is fulfilled. Control variables include sector and year dummies.

dummies.

Though the estimates from the probit for expansion in the initial period have no structural interpretation, the coefficient on the unobserved time-invariant error term $\tau_{i}$ is positive and significant at the $1 \%$ level which indicates that selection in the initial period is indeed positively correlated with the unobserved heterogeneity term that is fixed over time $\tau_{i} \cdot{ }^{8}$ We also checked the results of the selection equation when only estimating the model as a probit model and a random-effects model without controlling for the initial conditions. The results for these specifications indicate that the coefficient on the lagged expansion dummy is biased upwards in both the

\footnotetext{
${ }^{8}$ Results are not reported here but are available from the corresponding author.
} 
models, and the random-effects probit model can no longer identify the variance of the time-invariant error term $\sigma_{\tau}^{2}$. This highlights the importance of controlling for initial conditions when estimating such a model.

The results for the decision to expand can be compared to the decision to invest. Using the same approach as above, a dynamic random-effects probit model is estimated where the dependent variable is now equal to 1 when total investment is non-zero and 0 otherwise. As displayed in Table 4 in Appendix C, the coefficient on the lagged dependent variable is positive but in contrast to the decision to expand, it is highly insignificant. This reflects that the decision to make an investment includes adjustments such as the replacement of capital stock, which are undertaken regardless of the investments made in the previous year.

\section{Multiple-regime model}

In the next stage, we estimate equation (2) separately for the high and low regimes to investigate whether total investment responds differently to fundamentals over these regimes. By comparing the results in column (1) to column (3) in Table 3 , we see that firm investment is more responsive to the lagged sales-capital ratio in the high regime than in the low one, and that this relationship is marginally concave in both regimes. These results imply that total investment rate is nonlinear with respect to fundamentals and is consistent with the proposition that investment is separated into two regimes. An explanation for this result is that firms' decisions regarding replacement of capital stock are less affected by fundamentals as represented by the sales-capital ratio. As conditions improve, firms find it optimal to incur the extra fixed cost when expanding. Once firms operate in the high regime where they invest in both the replacement and expansion of capital stock, total investment becomes more responsive to the level of the lagged sales-capital ratio. Hence, there is no evidence here that the investment profile is sigmodial as proposed by Abel and Eberly (2001) and Barnett and Sakellaris (1998), who found that the response of investment to Tobin's $q$ is smaller in the high q regime than in the low $q$ regime. However, the focus in this paper is on the response of investment to 
Table 3: Multiple Regime Model

\begin{tabular}{|c|c|c|c|c|}
\hline \multicolumn{5}{|c|}{ Dependent variable: $(I / K)$} \\
\hline & \multicolumn{2}{|c|}{ High regime } & \multicolumn{2}{|c|}{ Low regime } \\
\hline & OLS & OLS & OLS & OLS \\
\hline Variable & $(1)$ & $(2)$ & $(3)$ & $(4)$ \\
\hline \multirow[t]{2}{*}{ 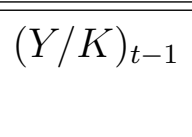 } & $0.029 * * *$ & $0.029 * * *$ & $0.016^{* * *}$ & $0.017 * * *$ \\
\hline & $(0.004)$ & $(0.004)$ & $(0.005)$ & $(0.005)$ \\
\hline \multirow[t]{2}{*}{$(Y / K)_{t-1}^{2}$} & $-0.001^{* * *}$ & $-0.001^{* * *}$ & -0.001 & -0.001 \\
\hline & $(0.0003)$ & $(0.0003)$ & $(0.001)$ & $(0.001)$ \\
\hline \multirow[t]{2}{*}{$B 1_{i}$} & - & 0.011 & - & 0.009 \\
\hline & - & $(0.007)$ & - & $(0.011)$ \\
\hline \multirow[t]{2}{*}{$B 2_{i t}$} & - & -0.006 & - & -0.008 \\
\hline & - & $(0.027)$ & - & $(0.024)$ \\
\hline No. Obs. & 734 & 734 & 304 & 304 \\
\hline$R^{2}$ & 0.27 & 0.28 & 0.22 & 0.23 \\
\hline
\end{tabular}

Source: IAB Establishment Panel 1996-2001. *** - 1\% significance level, ${ }^{* *}-5 \%$ significance level,* - 10\% significance level. Robust standard errors are reported corrected for heteroskedasticity and clustering at the establishment level. Control variables include sector and year dummies.

lagged sales-capital ratio over two regimes which are determined by whether firms expand capital stock or not. In these other studies, the separation of the regimes is not observed but instead estimated. Therefore, the results here are not directly comparable with those of the previous literature, but indicate that the previous results may not be consistent with firm investment decisions.

Finally, the coefficient on the year dummy for 1998 is positive and significant for the high regime, while the year dummy for 2001 is negative and significant at the $1 \%$ level in all specifications. This is consistent with the macroeconomic conditions 
in Germany during this period. In the high regime it is evident that the consumer good industry has a lower total investment rate in comparison to the machinery industry. In the low regime, the results suggest that the consumer good has on average a lower and the chemical and petroleum products industries a higher total investment rate in comparison to the machinery industry.

We re-estimate equation (2) using the bias correction terms, $B 1_{i}$ and $B 2_{i t}$, as additional regressors in the high and low regime specifications. In the case of both regimes, as shown in column (2) and (4) of Table 3, there is no evidence of selection bias. $^{9}$ Furthermore, the inclusion of the bias correction terms does not have a significant effect on the coefficient estimates. This may also reflect that this bias is not identified, which is a problem given the strong assumptions for the parametric two-step methodology.

\section{Robustness checks}

The above results are also checked by estimating the multiple-regime model, equation (2), jointly for both regimes. That is, the vector of control variables now include the variables interacted with the expansion dummy. The coefficients on these variables identify the difference of the impact of these factors on the investment rate in the high regime in comparison to the low regime. In this joint specification, the results are in line with those as presented in Table $3 .{ }^{10}$ Furthermore, there is no evidence that the coefficients for the sector and year dummies are significantly different for the two samples. Finally, we repeat the estimation of this joint model using the sample selection bias correction terms, $B 1_{i}$ and $B 2_{i t}$, also interacted with the expansion dummy. As before, there remains no evidence of sample selection bias.

We also checked the robustness of the results when using the balanced sub-

\footnotetext{
${ }^{9}$ The standard errors in the second-stage should be corrected since the two sample selection bias correction terms, $B 1_{i}$ and $B 2_{i t}$, are constructed using the predicted values from the random-effects probit model. In absence of this correction, standard errors are likely to be biased downwards. See Vella and Verbeek (1998) and Vella and Verbeek (1999) for further details. Our main conclusions are not affected by disregarding this correction.

${ }^{10}$ The results for the joint specification are not reported here but are available from the authors.
} 
sample and found that the estimates are not significantly different, which indicates that attrition bias is not likely to be influencing the coefficient estimates.

\section{Conclusion}

In this paper, we specify a model with two types of investment: replacement and expansion of capital stock. Both incur convex adjustment costs but expansion also entails a fixed cost. This results in a two regime model: a low regime where firms only invest in the replacement of capital stock; and a high regime where they invest in both replacement and expansion of capital. Earlier studies such as Barnett and Sakellaris (1998), Nilsen and Schiantarelli (2003), and Letterie and Pfann (2003) have looked for evidence of non-linearity of investment over various regimes where the separation is unobserved. Using the IAB Establishment Panel, we are able to observe the sample separation and test directly whether the investment rate is more responsive in the high regime in comparison to the low one. Moreover, the selection into the two regimes is likely to be endogenous. However, the presence of such a bias has not been thoroughly addressed in the empirical investment literature.

Our results for the selection equation, estimated as a random-effects probit model, indicate that expansion by German firms in this period is more continuous than lumpy. Given that the firms are on average very large in the sample used for estimation, this result is not surprising but it also suggests that firms are spreading investment in the expansion of the capital stock over a period of years rather than confining their investments to a single year. Secondly, the results for the multiple-regime model reveal that the investment rate is non-linear in response to fundamentals, such that the investment rate is more responsive to the lagged sales-capital ratio in the high regime, where firms replace and expand capital stock, than in the low regime, where they only invest in replacement. Thus, there is no indication that the profile of the investment rate with respect to fundamentals is sigmodial as found in previous studies mentioned in the previous paragraph.

In past studies, the empirical identification of non-linearities in investment relied on how investment is assumed to be separated into various regimes. In this paper, we 
demonstrate that this may not be consistent with the underlying differences in firm investment decisions. With further waves of data it will be possible to investigate how these results generalise to a longer period which will enable a broader analysis of firm-level investment in the presence of non-convex adjustment costs and the non-linearity of their investment profile. 


\section{References}

Abel, A., And J. Eberly (1994): "A Unified Model of Investment under Uncertainty," American Economic Review, 84(5), 1369-1384.

(2001): "Investment and Q with Fixed Costs: An Empirical Analysis," Working Paper.

Barnett, S., And P. Sakellaris (1998): "Nonlinear Response of Firm Investment to Q: Testing a Model of Convex and Non-Convex Adjustment Costs," Journal of Monetary Economics, 42, 261-288.

Caballero, R., E. Engel, and J. Haltiwanger (1995): "Plant-Level Adjustment and Aggregate Investment Dynamics," Brookings Papers on Economic Activity, 1995(2), 1-39.

Chamberlain, G. (1980): "Analysis of Covariance with Qualitative Data," Review of Economic Studies, 47(1), 225-238.

Cooper, R., J. Haltiwanger, and L. Power (1999): "Machine Replacement and the Business Cycle: Lumps and Bumps," American Economic Review, 89(4), 921-946.

Doms, M., And T. Dunne (1998): "Capital Adjustment Patterns in Manufacturing Plants," Review of Economic Dynamics, 1, 409-429.

Griliches, Z., and J. Hausman (1986): "Errors in Variables in Panel Data," Journal of Econometrics, 31, 93-118.

Hayashi, F. (1982): "Tobin's Marginal Q and Average Q: A Neoclassical Interpretation," Econometrica, 50(1), 213-224.

Heckman, J. (1981): "The Incidental Parameters Problem and the Problem of Initial Condtions in Estimating a Discrete Time-Discrete Data Stochastic Process," in Structural Analysis of Discrete Data with Econometric Applications, ed. by C. Manski, and D. McFadden, pp. 179-195. MIT Press, Cambridge, MA. 
Hu, X., and F. Schiantarelli (1998): "Investment and Capital Market Imperfections: A Switching Regression Approach Using U.S. Firm Panel Data," Review of Economics and Statistics, 80(3), 466-479.

Letterie, W., and G. Pfann (2003): "On the Identification of High and Low Regimes in Equipment Investment Expenditures of Firms," Working Paper.

Nickell, S. (1978): The Investment Decision of Firms. Cambridge Uni. Press, Cambridge.

Nilsen, O., and F. Schiantarelli (2003): "Zeros and Lumps in Investment: Empirical Evidence on Irreversibilities and Nonconvexities," Review of Economics and Statistics, 85, 1021-1037.

Rothschild, M. (1971): "On the Cost of Adjustment," Quarterly Journal of Economics, 85(4), 605-622.

Vella, F., And M. Verbeek (1998): "Whose Wages Do Unions Raise? A Dynamic Model of Unionism and Wage Rate Determination for Young Men," Journal of Applied Econometrics, 13, 163-183.

_ (1999): "Two-Step Estimation of Panel Data Models with Censored Endogenous Variables and Selection Bias," Journal of Econometrics, 90, 239-263.

Wooldridge, J. (2002): "Simple Solutions to the Initial Conditions Problem in Dynamic Nonlinear Panel Data Models with Unobserved Heterogeneity," CEMMAP Working Paper, CWP 18/02. 


\section{A Derivation of bias correction terms}

Here we follow the derivation of Vella and Verbeek (1999). The term $E\left[v_{i t}^{n} \mid \pi_{i}, \pi_{i 0}, z_{i}\right]$ in (6) can be derived as

$$
E\left[v_{i t}^{n} \mid \pi_{i}, \pi_{i 0}, z_{i}\right]=\int_{-\infty}^{\infty}\left[\tau_{i}+E\left[\theta_{i t} \mid \pi_{i}, \pi_{i 0}, z_{i}\right]\right] f\left(\tau_{i} \mid \pi_{i}, \pi_{i 0}, z_{i}\right) d \tau_{i}
$$

The term $E\left[\theta_{i t} \mid \pi_{i}, \pi_{i 0}, z_{i}\right]$ is equal to the cross-sectional generalised residual from estimation of the probit model consisting of equation (4) and is given by

$$
E\left[\theta_{i t} \mid \pi_{i}, \pi_{i 0}, z_{i}\right]=\left(2 \pi_{i t}-1\right) \frac{\phi\left(y_{i t}\right)}{\Phi\left(y_{i t}\right)},
$$

where $y_{i t}=\left(2 \pi_{i t}-1\right)\left(\eta \pi_{i, t-1}+\gamma^{\prime} z_{i t}+\tau_{i}\right)$, which is used to save specifying separate terms for when $\pi_{i t}=1$ and $\pi_{i t}=0 . \phi(\cdot)$ and $\Phi(\cdot)$ are the probability density function of the standard normal distribution and cumulative distribution function, respectively. The second term in equation (7) that needs to be derived is the conditional density of $\tau_{i}$ given selection, and $z_{i}$, which is equal to

$$
f\left(\tau_{i} \mid \pi_{i}, \pi_{i 0}, z_{i}\right)=\frac{f\left(\pi_{i}, \pi_{i 0} \mid z_{i}, \tau_{i}\right) f\left(\tau_{i}\right)}{f\left(\pi_{i}, \pi_{i 0} \mid z_{i}\right)} .
$$

For the derivation of the terms in equation (9) we use Assumptions 1 and 2 and assume as per Heckman (1981) that the marginal distribution is approximated by a probit model using all pre-sample information and where no restrictions are placed on the correlation of the error terms between this probit and those in the selection equation for the remaining periods. This implies the following latent model for expansion in the initial period $\pi_{i 0}^{*}=\Lambda^{\prime} W_{i 0}+\xi \tau_{i}+a_{i 0}$, such that $\pi_{i 0}=1$ if $\pi_{i 0}^{*}>0$ and equals 0 otherwise, and where $W_{i 0}$ is a vector of pre-sample regressors, and $\xi$ is a parameter to be estimated and identifies whether or not expansion in the initial period is correlated with the unobserved time-invariant term, $\tau_{i}$. $a_{i 0}$ is assumed to be normally distributed.

This allows us to specify the joint probability of selection in the denominator of equation (9) as 


$$
\begin{aligned}
f\left(\pi_{i}, \pi_{i 0} \mid z_{i}\right)= & \int_{-\infty}^{\infty} f\left(\pi_{i}, \pi_{i 0} \mid z_{i}, \tau_{i}\right) f\left(\tau_{i}\right) d \tau_{i} \\
= & \int_{-\infty}^{\infty}\left[\prod_{s=1}^{T_{i}} \Phi\left(\left(2 \pi_{i s}-1\right)\left(\eta \pi_{i, s-1}+\gamma^{\prime} z_{i s}+\tau_{i}\right)\right)\right] \\
& \cdot \Phi\left(\left(2 \pi_{i 0}-1\right)\left(\Lambda^{\prime} W_{i 0}+\xi \tau_{i}\right)\right) \frac{1}{\sigma_{\tau}} \phi\left(\frac{\tau_{i}}{\sigma_{\tau}}\right) d \tau_{i}
\end{aligned}
$$

where $\phi\left(\frac{\tau_{i}}{\sigma_{\tau}}\right)=\frac{1}{\sqrt{2 \pi}} e^{-\frac{1}{2} \frac{\tau_{i}^{2}}{\sigma_{\tau}^{2}}}$. Note that because we use an unbalanced panel, the number of periods that a firm appears in the panel varies and thus selection is combined over periods $T_{i}$ for each firm $i$. Using the above expressions, we can reformulate the conditional distribution of $\tau_{i}$ given selection, $f\left(\tau_{i} \mid \pi_{i}, \pi_{i 0}, z_{i}\right)$ (9) as

$$
f\left(\tau_{i} \mid \pi_{i}, \pi_{i 0}, z_{i}\right)=\frac{\left[\prod_{s=1}^{T_{i}} \Phi\left(y_{i s}\right)\right] \Phi\left(x_{i o}\right) \frac{1}{\sigma_{\tau}} \phi\left(\frac{\tau_{i}}{\sigma_{\tau}}\right)}{\int_{-\infty}^{\infty}\left[\prod_{s=1}^{T_{i}} \Phi\left(y_{i s}\right)\right] \Phi\left(x_{i o}\right) \frac{1}{\sigma_{\tau}} \phi\left(\frac{\tau_{i}}{\sigma_{\tau}}\right) d \tau_{i}},
$$

where $x_{i o}=\left(2 \pi_{i 0}-1\right)\left(\Lambda^{\prime} W_{i 0}+\xi \tau_{i}\right)$. The denominator of (11) is programmed and estimated using the maximum likelihood facility in Stata. This requires the approximation of the likelihood contribution of firm $i$ over all periods $T_{i}$, where we use the following transformation $r_{i}=\tau_{i} / \sqrt{2} \sigma_{\tau}$. Note that this is exactly the likelihood function for the random-effects probit model accounting for the initial conditions.

$$
\begin{aligned}
l_{i}= & \int_{-\infty}^{\infty}\left[\prod_{s=1}^{T_{i}} \Phi\left(y_{i s}\right)\right] \Phi\left(x_{i o}\right) \frac{1}{\sigma_{\tau}} \frac{1}{\sqrt{2 \pi}} e^{-\frac{1}{2} \frac{\tau_{i}^{2}}{\sigma_{\tau}^{2}}} d \tau_{i} \\
= & \frac{1}{\sigma_{\tau} \sqrt{2 \pi}} \int_{-\infty}^{\infty}\left[\prod _ { s = 1 } ^ { T _ { i } } \Phi \left(( 2 \pi _ { i s } - 1 ) \left(\eta \pi_{i, s-1}+\gamma^{\prime} z_{i s}\right.\right.\right. \\
& \left.\left.\left.+r_{i} \sqrt{2} \sigma_{\tau}\right)\right)\right] \Phi\left(\left(2 \pi_{i 0}-1\right)\left(\Lambda^{\prime} W_{i 0}+\xi \tau_{i}\right)\right) e^{-r_{i}^{2} \sqrt{2} \sigma_{\tau} d r_{i}} \\
\approx & \frac{1}{\sqrt{\pi}} \sum_{m=1}^{M}\left\{\omega_{m}^{*}\left[\prod_{s=1}^{T_{i}} \Phi\left(\left(2 \pi_{i s}-1\right)\left(\eta \pi_{i, s-1}+\gamma^{\prime} z_{i s}+\psi r_{m}^{*}\right)\right)\right]\right. \\
& \left.\cdot \Phi\left(\left(2 \pi_{i 0}-1\right)\left(\Lambda^{\prime} W_{i 0}+\xi \psi r_{m}^{*}\right)\right)\right\}
\end{aligned}
$$


where $\omega_{m}^{*}$ and $r_{m}^{*}$ are the Gauss-Hermite quadrature weights and nodes. $\psi=$ $(2 \rho /(1-\rho))^{1 / 2}$ where $\rho=\left(\sigma_{\tau}^{2} /\left(\sigma_{\tau}^{2}+1\right)\right)$, which is the proportion of the total variance of the error term due to the time-invariant firm effect. Given the parameter estimates, $\hat{\gamma}, \hat{\eta}, \hat{\Lambda}, \hat{\xi}$, and $\hat{\sigma}_{\tau}^{2}$, from estimation of the random-effects probit model, (12), we can solve for equation (7), which also requires an approximation using Gauss-Hermite quadrature. Using the same transformation as above in (12), we can approximate equation (7) as the following

$$
\begin{aligned}
& \int_{-\infty}^{\infty}\left[\hat{\tau}_{i}+\left(2 \pi_{i t}-1\right) \frac{\phi\left(\hat{y}_{i t}\right)}{\Phi\left(\hat{y}_{i t}\right)}\right] \frac{\prod_{s=1}^{T_{i}} \Phi\left(\hat{y}_{i s}\right) \Phi\left(\hat{x}_{i 0}\right) \frac{1}{\hat{\sigma}_{\tau}} \phi\left(\frac{\hat{\tau}_{i}}{\hat{\sigma}_{\tau}}\right)}{\hat{l}_{i}} d \tau_{i} \\
= & \frac{1}{\hat{\sigma}_{\tau} \sqrt{2 \pi}} \int_{-\infty}^{\infty}\left[\sqrt{2} \hat{\sigma}_{\tau} r_{i}+\left(2 \pi_{i t}-1\right)\right. \\
\cdot & \left.\frac{\phi\left(\hat{\eta} \pi_{i, t-1}+\hat{\gamma}^{\prime} z_{i t}+r_{i} \sqrt{2} \hat{\sigma}_{\tau}\right)}{\Phi\left(\left(2 \pi_{i t}-1\right)\left(\hat{\eta} \pi_{i, t-1}+\hat{\gamma}^{\prime} z_{i t}+r_{i} \sqrt{2} \hat{\sigma}_{\tau}\right)\right)}\right] \\
\cdot & {\left[\prod_{s=1}^{T_{i}} \Phi\left(\left(2 \pi_{i s}-1\right)\left(\hat{\eta} \pi_{i, s-1}+\hat{\gamma}^{\prime} z_{i s}+r_{i} \sqrt{2} \hat{\sigma}_{\tau}\right)\right)\right] } \\
\cdot & \frac{\Phi\left(\left(2 \pi_{i 0}-1\right)\left(\hat{\Lambda}^{\prime} W_{i 0}+\hat{\xi} r_{i} \sqrt{2} \hat{\sigma}_{\tau}\right)\right.}{\hat{l}_{i}} e^{-r_{i}^{2}} d r_{i} \\
\approx & \frac{1}{\sqrt{\pi}} \sum_{m=1}^{M} \omega_{m}^{*}\left\{\left[\hat{\psi} r_{m}^{*}+\left(2 \pi_{i t}-1\right) \frac{\phi\left(\hat{\eta} \pi_{i, t-1}+\hat{\gamma}^{\prime} z_{i t}+\hat{\psi} r_{m}^{*}\right)}{\Phi\left(\left(2 \pi_{i t}-1\right)\left(\hat{\eta} \pi_{i, t-1}+\hat{\gamma}^{\prime} z_{i t}+\hat{\psi} r_{m}^{*}\right)\right)}\right]\right. \\
\cdot & \left.\frac{\left[\prod_{s=1}^{T_{i}} \Phi\left(\left(2 \pi_{i s}-1\right)\left(\hat{\eta} \pi_{i, s-1}+\hat{\gamma}^{\prime} z_{i s}+\hat{\psi} r_{m}^{*}\right)\right)\right] \Phi\left(\left(2 \pi_{i 0}-1\right)\left(\hat{\Lambda}^{\prime} W_{i 0}+\hat{\xi} \hat{\psi} r_{m}^{*}\right)\right.}{l_{i}}\right\} \\
\equiv & C_{i t},
\end{aligned}
$$

where $\omega_{m}^{*}$ and $r_{m}^{*}$ are the Gauss-Hermite quadrature weights and nodes as before, and $\hat{l}_{i}$ is the denominator of (11) using the parameter estimates from the randomeffects probit model, equation (12). Finally we can calculate the terms in equations (6) as a function of $C_{i t}$

$$
\begin{aligned}
E\left[v_{i t}^{n} \mid \pi_{i}, \pi_{i 0}, z_{i}\right] & =\sigma_{n, \mu \tau}\left(\frac{1}{1+T_{i} \hat{\sigma}_{\tau}^{2}} \sum_{s=1}^{T_{i}} C_{i s}\right)+\sigma_{n, \epsilon \theta}\left(C_{i t}-\frac{\hat{\sigma}_{\tau}^{2}}{1+T_{i} \hat{\sigma}_{\tau}^{2}} \sum_{s=1}^{T_{i}} C_{i s}\right) \\
& \equiv \lambda_{1 n} B 1_{i}+\lambda_{2 n} B 2_{i t} .
\end{aligned}
$$




\section{B Description of data}

The IAB Establishment Panel is used for estimation, which is a German establishment panel dataset administered by the Institut für Arbeitsmarkt- und Berufsforschung, Bundesagentur für Arbeit. ${ }^{11}$ The panel commenced in 1993 and is retrospective, such that information collected in 1993 is for investment, sales, etc in the previous year, 1992. The panel used for estimation consists of large West German manufacturing establishments (sectors 15-36 following the NACE-1 classification). Outliers are dropped from the sample which are defined as observations where: 1. The studentised-residual resulting from the estimation of the primary equation is larger in absolute value than 2; and, 2. The leverage of the observation is greater than $(2 k+2 / n)$, where $k$ is the number of regressors and $n$ is the number of observations in the sample. The following variables are used in the estimation of the various models:

- Total real investment $I$ - total sum of investment over the year as reported by firms in DM deflated by the price index for investment goods, $p_{k}$, where $I=I^{r}+I^{e}$

- Real expansion investment $I^{e}$ - part of I that is for expansion of the capital stock, deflated by $p_{k}$;

- Real replacement investment $I^{r}$ - amount of I that is for replacement of capital stock, $I^{r}=I-I^{e}$, deflated by $p_{k}$;

- Real turnover/sales $Y$ - total turnover/sales over the year as reported by firms in DM deflated by the sector-level (two-digit) producer price index, $p$, $1995=100 ;^{12}$

- Capital stock $K$ - proxy for capital stock using observations of investment and sales from 1992-1995. $K_{t}$ denotes the capital stock at the beginning of period

\footnotetext{
${ }^{11}$ See betriebspanel.iab.de for further details (in German only)

${ }^{12}$ Data series provided by the Statistisches Bundesamt Deutschland in their time-series data (Zeitreihen-service), see www-zr.destatis.de
} 
t. Using the perpetual inventory method, the capital stock in period $T$ can be found recursively as $K_{i T}=\sum_{t=1}^{T}(1-\delta)^{t-1} I_{i, T-t}+(1-\delta)^{T} K_{i 0}$, where $\delta$ is the depreciation rate which we assume to be constant and equal to 0.05. Following Letterie and Pfann (2003), a value for $K_{i 0}$ can be obtained by assuming that the capital stock of the firm grows at a rate equal to the growth in the firm's output. This can be formulated as $K_{i T}=\prod_{t=1}^{T}\left(1+g_{i t}\right) K_{i 0}$, where the growth rate in period $t$ is equal to $g_{i t}=\left(Y_{i t}-Y_{i, t-1}\right) / Y_{i, t-1}$ and where $Y_{t}$ is the turnover/sales in year $t$. Now we have two equations with two unknowns $K_{i 0}$ and $K_{i T}$. Thus we can simply solve for the latter as

$$
K_{i T}=\frac{\sum_{t=1}^{T}(1-\delta)^{t-1} I_{i, T-t}}{1-\frac{(1-\delta)^{T}}{\prod_{t=1}^{T}\left(1+g_{i t}\right)}}
$$

Given a period of observations on investment, output and the depreciation rate, one can construct a capital stock measure for the year $T$. For periods $\{T+1, T+2, \ldots\}$, the capital stock measure is calculated using the perpetual inventory method $K_{i t}=I_{i, t-1}+(1-\delta) K_{i, t-1}$. Due to the short panel used in the paper, only 3 years of data are employed to construct the capital stock measure;

- Price index for investment goods $p_{k}$ - sector-level (two-digit) time-series data;

- Producer price index $p$ - official sector-level (two-digit) time-series data as provided by the Statistisches Bundesamt in their Zeitreihen-service, 1995=100.

Typically in Q models, average $\mathrm{q}$ is constructed as the following

$$
q=\frac{V}{p_{k} K},
$$

where $V$ is the value of the firm for which the stock market valuation is used. However, the IAB Establishment Panel contains no stock market information and thus we are required to use a proxy, for which we use the lagged sales-capital ratio $Y / K_{t-1}$. 


\section{Tables}

Table 4: Selection Equation - Total Investment

\begin{tabular}{lc}
\hline \hline Dependent variable: $\mathcal{I}\left(I_{t} \neq 0\right)$ & \\
\hline Variable & Coefficient \\
\hline \hline $\mathcal{I}\left(I_{t-1} \neq 0\right)$ & 0.682 \\
& $(0.737)$ \\
$(Y / K)_{t-1}$ & 0.124 \\
& $(0.169)$ \\
$(Y / K)_{t-1}^{2}$ & -0.014 \\
& $(0.013)$ \\
$\rho$ & $0.870 * * *$ \\
No. Obs. & $(0.109)$ \\
Log likelihood & 1192 \\
\hline \hline
\end{tabular}

Source: IAB Establishment Panel 1996-2001. *** - 1\% significance level,** - 5\% significance level, ${ }^{*}-10 \%$ significance level. $\mathcal{I}$ is an indicator variable and equals 1 if the condition inside the parentheses is fulfilled. Control variables include sector and year dummies. 